\title{
Advanced Oil Recovery Technologies for Improved Recovery From Slope Basin Clastic Reservoirs, Nash Draw Brushy Canyon Pool, Eddy County, New Mexico
}

\author{
Quarterly Report \\ January 1 - March 31, 1997
}

\author{
By \\ Mark B. Murphy
}

Work Performed Under Contract No.: DE-FC22-95BC14941

For

U.S. Department of Energy

Office of Fossil Energy

Federal Energy Technology Center

P.O. Box 880

Morgantown, West Virginia 26507-0880

By

Strata Production Company

P. O. Box 1030

Roswell, New Mexico 88202 


\section{Disclaimer}

This report was prepared as an account of work sponsored by an agency of the United States Government. Neither the United States Government nor any agency thereof, nor any of their employees, makes any warranty, express or implied, or assumes any legal liability or responsibility for the accuracy, completeness, or usefulness of any information, apparatus, product, or process disclosed, or represents that its use would not infringe privately owned rights. Reference herein to any specific commercial product, process, or service by trade

name, trademark, manufacturer, or otherwise does not necessarily constitute or imply its endorsement, recommendation, or favoring by the United States Government or any agency thereof. The views and opinions of authors expressed herein do not necessarily state or reflect those of the United States Government or any agency thereof. 


\title{
QUARTERLY TECHNICAL PROGRESS REPORT (Sixth Quarter)
}

\section{ADVANCED OIL RECOVERY TECHNOLOGIES FOR IMPROVED RECOVERY FROM SLOPE BASIN CLASTIC RESERVOIRS, NASH DRAW BRUSHY CANYON POOL, EDDY COUNTY, NM}

DOE Cooperative Agreement No. DE-FC-95BC14941

\author{
Strata Production Company \\ P.O. Box 1030 \\ Roswell, NM 88202 \\ (505) 622-1127
}

Date of Report:

Award Date:

Anticipated Completion Date:

Award Amount for Current Fiscal Year:

Award Amount for Budget Period I:

Name of Project Manager:

Contracting Officer's

Representative:

Reporting Period:
April 30, 1997

September 25, 1995

September 24, 1997 - Budget Period I

September 25, 2000 - Budget Period II

$\$ 2,011,213$

$\$ 3,354,067$

Mark B. Murphy

Mary Beth Pearse

January 1 - March 31, 1997

US/DOE Patent Clearance is not required prior to the publication of this document. 


\section{PROJECT OBJECTIVE}

The overall objective of this project is to demonstrate that an advanced development drilling and pressure maintenance program based on advanced reservoir management methods can significantly improve oil recovery. The plan includes developing a control area using standard reservoir management techniques and comparing its performance to an area developed using advanced methods. A key goal is to transfer advanced methodologies to oil and gas producers in the Permian Basin and elsewhere, and throughout the U.S. oil and gas industry.

\section{SUMMARY OF TECHNICAL PROGRESS}

This sixth quarterly progress report summarizes the results obtained to date on this project.

\section{MANAGEMENT AND PROJECT PLANNING}

Geological, engineering, geophysical, and simulation teams continue to gather and analyze data. A preliminary reservoir simulation was performed based on data entered into the geologic model. Target drilling areas have been identified from interpreted 3-D seismic data; the first target well was drilled in March 1997.

Communication and coordination between team members located in diverse geographic areas have been accomplished through state-of-the-art communication systems, including e-mail, the Internet, and high capacity data transfer. Successful data exchange among team members has helped in meeting project reporting requirements.

\section{Geology}

The Nash Draw Unit \#29 well was drilled in March 1997. The location for the well was picked using the seismic anomaly associated with the "L" Sand reflection amplitudes. The "L" Sand was encountered in the anticipated structural position relative to the other wells in the field. The porosity and sand development was not of the quality of similar reflection amplitudes in other parts of the field. It is possible the sand characteristics in this area have given similar amplitude attenuation, but for reasons other than thick porosity. The sand is more highly interbedded with shales than are other wells in the field.

Closer examination of the seismic data on a trace-by-trace basis suggests that the location of the well is actually on the northern edge of the higher amplitudes. If this is the case, we should still have relatively good connectivity to better quality sands. The geophysical group is currently in the process of integrating data from the well into the $3-\mathrm{D}$ volume. A digital array sonic log was run in the well. The data will facilitate calibration of the seismic velocities and may help us understand the amplitude variations in these sands.

The nature of the log character suggests that the southern limit of this particular depositional complex is nearby. Offset wells south of the unit have a very similar, lower quality sand development indicating a very distal portion of the fan complex. 
A poster session for this project was presented at the annual American Association of Petroleum Geologists held in Dallas, Texas, in early April 1997. The Advanced Log Analysis was well received at this international forum, and many positive comments were made with regard to the practical application it has in solving a fundamental problem in the Delaware Sands-specifically, its ability to accurately predict net pay and OOIP in thin bedded turbidite reservoirs. The approach can be readily applied to other turbidite reservoirs world wide. Other positive comments were made about the team's approach to solving problems by applying affordable, sound technology and getting meaningful and useful results.

\section{Engineering}

The Nash Draw Unit \#29 was drilled as a data well to test targeted drilling based on seismic anomalies. The well resulted in an "L" Zone with $5.24 \mathrm{~m}(16.0 \mathrm{ft})$ of net pay (NP) with a weighted average porosity of 12.52 percent, for a total of 0.6572 porosity-meters [(2.0032 porosity-feet (PF)]. The expected values from the seismic amplitude calculations indicated a well with 0.9508 porosity-meters $(2.898 \mathrm{PF})$ and $7.3430 \mathrm{~m} \mathrm{NP}(22.38153 \mathrm{ft} \mathrm{NP})$. The predicted values varied by approximately 40 percent from the actual values seen in the well. The task now is to investigate possible parameters which may effect these calculations such as variances in gross intervals and total porosity feet.

Completion of this well will occur in May 1997. Different frac treatment designs are being modeled to achieve maximum length without height growth into water producing zones. Different combinations of rates, pressures, fluid viscosity, and sand concentrations are being modeled to achieve a $131.23 \mathrm{~m}(400 \mathrm{ft})$ fracture length and $328.08 \mathrm{~m}(100 \mathrm{ft})$ fracture height.

During the logging of the Nash Draw Unit \#29, a continuity test was performed with a Repeat Formation Testing Tool (RFT) to determine zones showing pressure changes due to offset well production. Two zones indicated lower reservoir pressures and one higher reservoir pressures than were previously known. A good test of the top sand in the " $\mathrm{L}_{\mathrm{a}}$ " interval indicated a pressure of $13,126.2 \mathrm{kPa}$ (1,904 psi), which is approximately $7,238.7 \mathrm{kPa}(1,050 \mathrm{psi})$ lower than the original reservoir pressure. This indicates communication with other wells in the field. Another zone in the " $\mathrm{L}_{d}$ " at $2,253.12 \mathrm{~m}$ (6867.5 ft.), indicated lower pressure by differentially "sticking" the tool, but a good seat was not obtained for gathering pressure data. Other zones in the " $\mathrm{K}$ ", "K-2" and " $\mathrm{L}$ " indicated original pressure and no communication with other producers. Problems were encountered in getting good seats for the tool pad, and only 20 percent of the tests were successful. The data are presented in Figure 1.

Application of the core-calibrated Advanced Log Analysis (ALA) Tool was performed on two other Delaware wells in southeast New Mexico with good results. The first application yielded a standard analysis similar to the Nash Draw. The second application yielded a new rock type, and a major correction in log values (14 percent) was necessary to accurately predict pay intervals. These wells are being completed and results will be available in the next quarter.

A directional/horizontal well is being designed to test a seismic amplitude anomaly under a playa lake. The plan is to deviate the well $385.17 \mathrm{~m}(1,174 \mathrm{ft})$ and then drill a $262.47 \mathrm{~m} \mathrm{(800} \mathrm{ft)} \mathrm{horizontal}$ section through the "L" zone. The bottomhole location will be $631.23 \mathrm{~m}(1,924 \mathrm{ft})$ west southwest of the surface location at $726.71 \mathrm{~m}(2,215 \mathrm{ft})$ FSL and $572.83 \mathrm{~m}(1746 \mathrm{ft})$ FWL of section 12, T23 S-R29E. This will be the first well to test targeted deviated/horizontal drilling to develop reserves under both the playa lakes and potash area. The well schematic is presented in Figure 2. 


\section{Reservoir Characterization/Reservoir Simulation}

Activities of the Reservoir Characterization/Simulation Team for the first quarter of 1997 were focused on the validation of a simulation model for the proposed pilot area centered around Nash Draw Unit \#1. A three-dimensional representation of the grid for this model is depicted in Figure 3. This model was based on the geological interpretation of the "L" zone of the Nash Draw Brushy Canyon reservoir that was refined over the last three quarters of 1996.

Although produced oil, water, and gas volumes are available for each of the five wells in the pilot area, pressure measurements are sparse (a single pressure test for Nash Draw Unit \#5).

Consequently, for each well attempts were made to match 1) drainage area average pressure (as opposed to bottomhole pressure), 2) water production, and 3) gas production.

The OOIP for each well was calculated assuming a 12 percent recovery factor, and the drainagearea average pressure was back-calculated from this assumption. Figure 4 shows the simulated pressure responses plotted for the five pilot wells during the quarter ending October 1, 1996. These represent the best results obtained to date. In general, all of the simulated drainage area pressures are too high. If we assume a 16.7 percent recovery factor for which there is a precedent in adjacent fields in the Delaware formation, we expect to be able to obtain a better match for the drainage area pressures. For this case, the pilot area total oil volume is only 1.91 MSTB, not the 3.59 MSTB of the present simulation model.

\section{Geophysical Activity}

Analysis of the instantaneous frequency displays, seismic volume, and pressure data have indicated parts of the "K" and "L" reservoirs are compartmentalized. For the Nash Draw 3-D seismic data, any frequency component calculated from the data that falls outside the range $\mathrm{O}$ to $120 \mathrm{~Hz}$ (the highest frequency created by the vibrators) is, by definition, an anomalous frequency value. When 3-D seismic data volumes are converted into 3-D volumes of instantaneous frequency, there is always a large number of anomalous frequency values distributed throughout the 3-D image space. Interpreters now know that these anomalous frequencies can be important indicators of stratigraphic discontinuities. Because stratigraphic discontinuities can infer where there are barriers to horizontal fluid flow, then instantaneous frequency displays can be used to infer where reservoir compartment boundaries exist.

Instantaneous frequency volumes were calculated from the Nash Draw 3-D data, and the instantaneous frequency behavior was then interpreted across several chronostratigraphic horizons passing through the "K" and "L" reservoir sequences. Using these interpretations, a tentative reservoir compartment model was developed for the " $\mathrm{K}$ " sequence across the Nash Draw Unit. This tentative compartment map is realistic in the sense that it indicates there are large compartments around the better producing wells (e.g, 11, 15, and 19) and segmented compartments at the poorer producers (e.g., 5, 6, and 25). If production modeling confirms that the compartment sizes and shapes suggested by this model are realistic, a more detailed compartment model can be developed for both the "K" and "L" sequences in those areas of the Nash Draw Unit where reservoir simulation studies are to be done. 


\section{TECHNOLOGY TRANSFER}

The transfer of technical information generated during the course of this project is a prime objective of the project. Toward this objective, Strata has participated in several meetings and workshops to promote the dissemination of information generated during this quarter. A summary of these activities is outlined.

Fourth International Reservoir Characterization Technical Conference - March 1997. Mr. Dave Martin presented a paper entitled "Advanced Reservoir Characterization for Improved Oil Recovery in a New Mexico Delaware Basin Project" at the Fourth International Reservoir Characterization Technical Conference held in Houston, Texas on March 2-4, 1997.

AAPG Annual Convention - April 1997. A poster session was presented at the AAPG Annual Convention to be held in Dallas, Texas, April 7-10. Bruce Uszynski presented an update of the status and findings at the Nash Draw Project review.

SPE Paper Accepted - A paper titled "Reservoir Characterization as a Risk Reduction Tool at the Nash Draw Pool," will be presented at the fall SPE Convention to be held in San Antonio, Texas, in October 1997.

Workshop - A reservoir characterization workshop is being planned for late summer 1997.

Internet Homepage: One of the pertinent technology transfer objectives was the rapid dissemination of the technology that had a direct influence on the characterization of the Nash Draw field. Towards this objective, the New Mexico Petroleum Recovery Research Center embarked upon creating an Internet homepage specifically dedicated to the Nash Draw project. This homepage may be accessed at the URL (address) http://baervan.nmt.edu/prrc/resdiv/react/reactnew.html. This address accesses the REACT (Reservoir Evaluation and Advanced Computational Technologies) homepage. By clicking on the REACT PROJECTS section, the NASH DRAW project may be accessed.

The current site is being modified to include the previous reports and the most recent annual report. The annual report will be included as a downloadable document from the Nash Draw Internet site available at the URL address given above. 

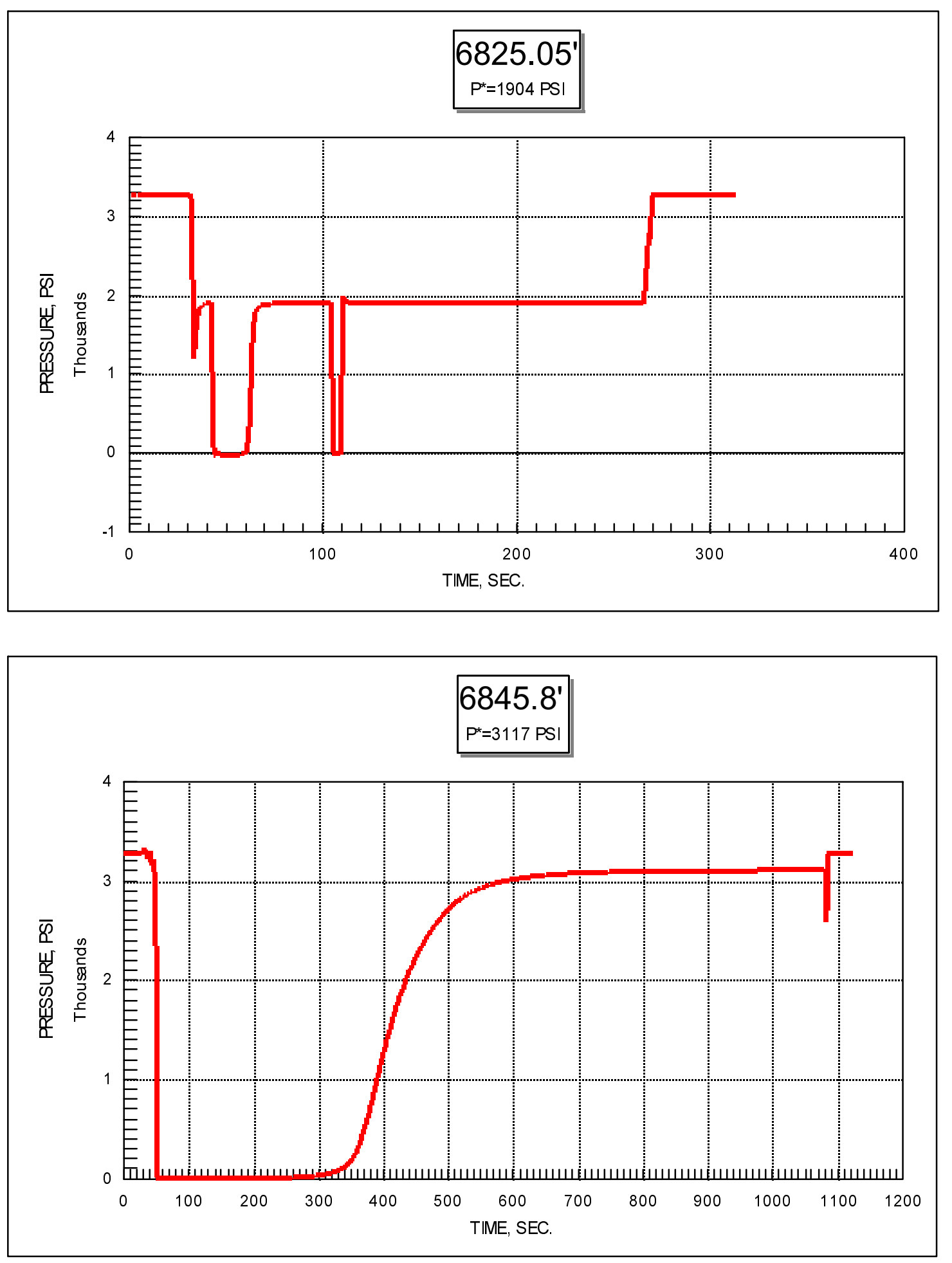

Fig. 1: Continuity test with RFT tool. 
Nash Draw \#36 Directional Well

Surface Location 2215' FSL \& 1746' FWL Section 12-T23S-R29E Eddy County, New Mexico

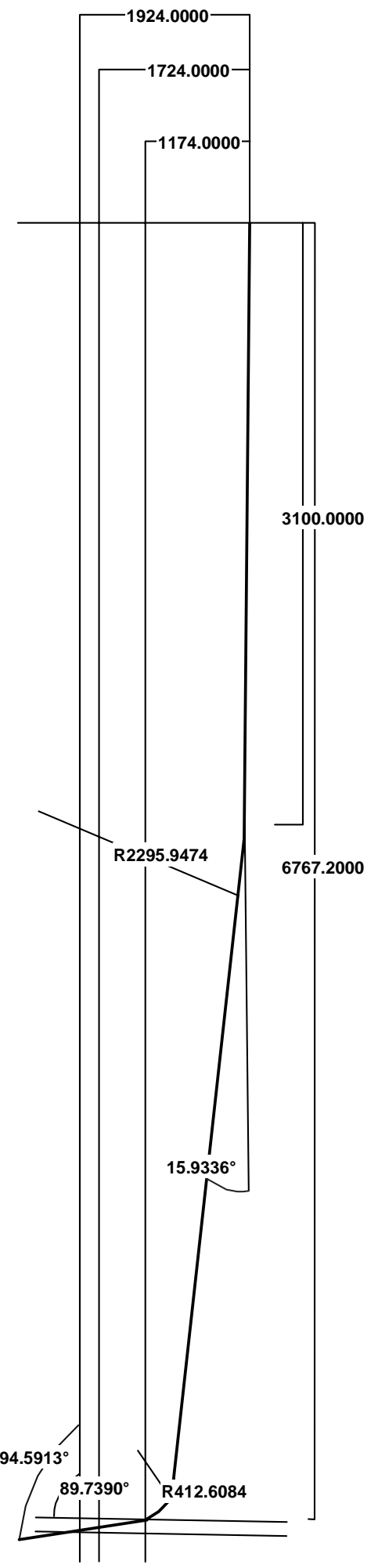

Fig. 2: Nash Draw Unit \#36 directional/horizontal well. 


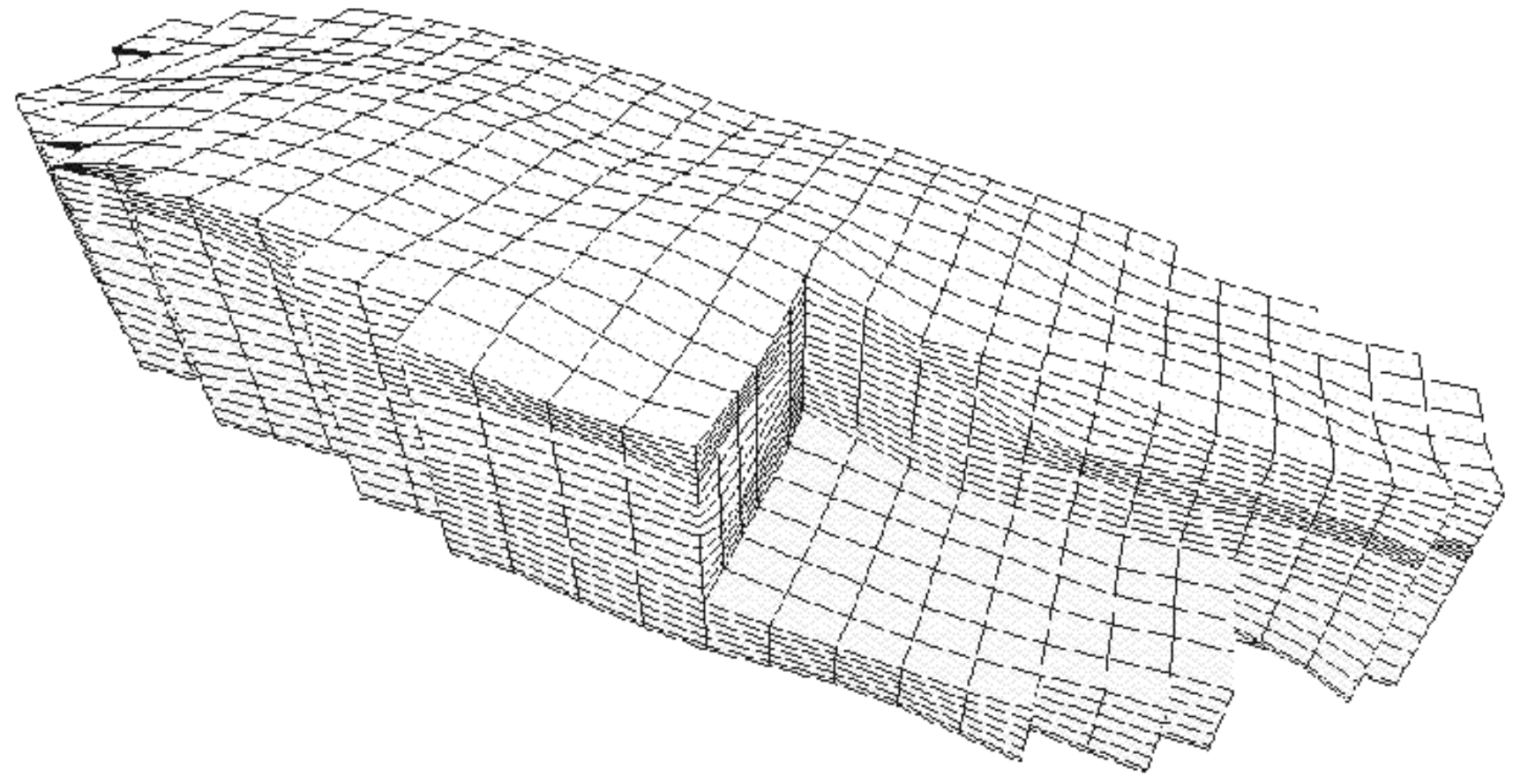

Fig. 3: Simulation grid for L-sand. 
Drainage Region

Pressure Match,

12\% Recovery Case

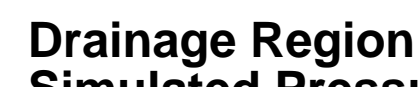

Simulated Pressure

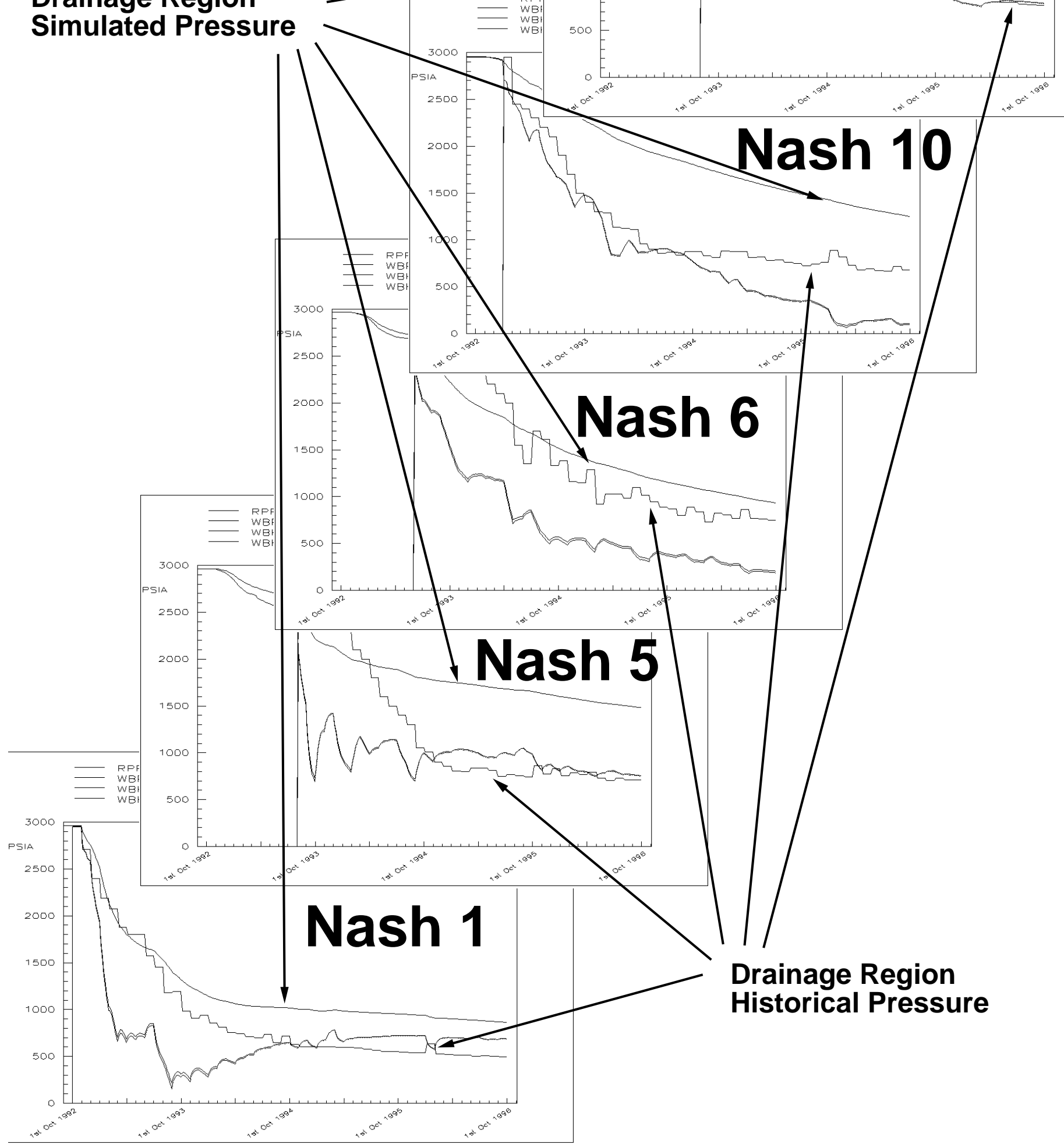

Fig. 4: Pressure profiles 